\title{
Influence of micro- and nanofillers on electro-mechanical performance of silicone EAPs
}

Skov, Anne Ladegaard; Bejenariu, Anca Gabriela; Bøgelund, Jesper; Benslimane, Mohamed; Daugaard, Anders Egede

\section{Published in:}

Proceedings of SPIE - The International Society for Optical Engineering

Link to article, DOI:

$10.1117 / 12.966008$

Publication date:

2012

Document Version

Early version, also known as pre-print

Link back to DTU Orbit

Citation (APA):

Skov, A. L., Bejenariu, A. G., Bøgelund, J., Benslimane, M., \& Daugaard, A. E. (2012). Influence of micro- and nanofillers on electro-mechanical performance of silicone EAPs. Proceedings of SPIE - The International Society for Optical Engineering, 8340, 83400M. https://doi.org/10.1117/12.966008

\section{General rights}

Copyright and moral rights for the publications made accessible in the public portal are retained by the authors and/or other copyright owners and it is a condition of accessing publications that users recognise and abide by the legal requirements associated with these rights.

- Users may download and print one copy of any publication from the public portal for the purpose of private study or research.

- You may not further distribute the material or use it for any profit-making activity or commercial gain

- You may freely distribute the URL identifying the publication in the public portal 


\title{
Influence of micro- and nanofillers on electro-mechanical performance of silicone EAPs
}

\author{
Anne Ladegaard Skov ${ }^{\mathrm{a}^{*}}$, Anca Bejenariu ${ }^{\mathrm{a}}$, Jesper Bøgelund ${ }^{\mathrm{b}}$, Mohamed Benslimane ${ }^{\mathrm{c}}$, Anders \\ Daugaard Egede ${ }^{\mathrm{a}}$ \\ ${ }^{a}$ DTU, Department of Chemical and Biochemical Engineering, Kgs. Lyngby, \\ ${ }^{\mathrm{b}}$ Danish Technological Institute, Høje Taastrup, Denmark \\ ${ }^{c}$ Danfoss PolyPower, Nordborg, Denmark
}

\begin{abstract}
The effect of different fillers on the mechanical and dielectric properties of soft elastomers has been investigated. It was found that the addition of a small amount of silica fillers would increase the Young's modulus significantly but not simultaneously increase the tear strength sufficiently for processing as thin films. Addition of nanoclay and barium titanate nanoparticles to the soft elastomers was shown to be very favorable for the enhancement of the dielectric properties without increasing the Young's modulus significantly and could be used for DEAP material in e.g. microprocessing where the tear strength is not crucial for processing. However, for elastomer film processing it is suggested that a combination of the nanoclay or barium titanate with either silica particles or bimodal networks would give the right tear strength together with the desired increased dielectric permittivity.
\end{abstract}

Keywords: silicone EAP, fillers, rheology, dielectrical permittivity

\section{INTRODUCTION}

Silicones are widely used in electroactive polymers formulation due to their favorable electro-mechanical properties, but they do, however, posses low mechanical breakdown strength and hence the mechanical properties must be improved ${ }^{1}$ both to ease the processing but also to optimize the performance of the EAP. A well-known technique to improve the tear strength of rubbers is to add micro- or nanofillers ${ }^{2}$.

The effects of different micro- and nanofillers on the electro-mechanical behavior of silicone based dielectric elastomer are studied in this work. Several types of fillers and varied loadings are used to increase the permittivity of the silicone networks. The effect of micro- and nanoparticles on the electrical and viscoelastic properties of a model silicone system is investigated. The presence of fillers produces a highly inhomogeneous electric field in the materials and also influences the dielectric permittivity of the film, simultaneously with the enhancement of the mechanical breakdown.

Dielectric electro-active polymers (DEAPs) which consist of an elastomer film with deposited electrodes on both sides have lately gained increased interest as materials for actuators, generators, and sensors. Most demonstrated actuators do, however, rely on commercially available materials such as VHB (3M), Sylgaard (Dow Corning) or Elastosil (Wacker Chemie) which haven't been developed and optimized with the requirements of DEAPs in mind. Hence, it is obvious that material optimization is crucial - and possible - for better DEAP performance. One problem for DEAP is the driving voltage of the material. If we look at the relation between the strain (p) and the voltage (U) (eq 1):

$$
p=\frac{\varepsilon_{0} \cdot \varepsilon_{r}}{Y}\left(\frac{U}{d_{1}}\right)^{2}
$$

we observe that a lowering of the required voltage for a given strain can be obtained if we either 1) increase the relative dielectric permittivity $\left.\left(\varepsilon_{\mathrm{r}}\right), 2\right)$ decrease the Young's modulus $(\mathrm{Y})$ or 3$)$ decrease the film thickness $\left(\mathrm{d}_{1}\right)$. Current largescale processing of DEAP films do not allow for a further significant thickness reduction, so in this study we focus on the combined alternation of the relative dielectric permittivity $\left(\varepsilon_{\mathrm{r}}\right)$ and the Young's modulus $(\mathrm{Y})$. There are of course - 
Return to your MySPIE To Do List at http://myspie.org and approve or disapprove this submission. Your manuscript will not be published without this approval. Please contact author_help@spie.org with any questions or concerns.

and unfortunately- several other material parameters that need to be taken into account during the optimization such as actuation response (usually all silicone systems are sufficiently fast), tear strength, maximal extension, mechanical hysteresis, electric breakdown strength and ease of processing amongst many others.

Since $\mathrm{Y}$ and $\varepsilon_{\mathrm{r}}$ are closely interrelated it is very important to do a combined optimization. Previous studies on the enhancement of $\varepsilon_{\mathrm{r}}$ have shown destruction of elasticity upon high loadings of filler particles either due to crystallinity effects $^{3,4}$ or solvent effects 5 .

Lately, silicone based networks with improved electromechanical properties suitable for actuators applications have been prepared $^{6}$. To improve the dielectric permittivity of the elastomers, different approaches have been investigated. Grafting of low molecular weight molecules with dipolar molecules onto silicone networks have been shown to give an improved permittivity. Presence of approximately $10 \%$ dipoles doubled the initial relative permittivity of the silicone networks $\left(\varepsilon^{\prime}=3.3\right)$ resulting in a final value of 6 while the Young's modulus $(\mathrm{Y})$ had an initial value of $340 \mathrm{kPa}$ and the dipoles presence increased $\mathrm{Y}$ to $1700 \mathrm{kPa} .{ }^{3}$ Alternatively, adding encapsulated conductive fillers such as coated polyaniline (PANI) into silicone networks have also been shown to be an effective approach ${ }^{5}$. Encapsulated PANI $(25 \%)$ in a hydroxyl end-functionalized silicone matrix resulted in a relative dielectrical permittivity of 4 and $\mathrm{Y}$ of $1770 \mathrm{kPa}$ at $0.5 \%$ strain compared to the initial properties of the pure elastomer $\left(\varepsilon^{\prime}=3.2\right)$ and $Y=1270 \mathrm{kPa}$ at $0.5 \% \operatorname{strain}^{5}$. As an alternative to enhancement of the tear strength by addition of silica particles, bimodal networks have also been investigated ${ }^{7}$. The idea behind the controlled heterogeneity in bimodal networks is that the densely crosslinked clusters within the network act in a way similar to filler particles, and easier handability of elastomer films due to the higher tear strength are obtained. Furthermore the elastic modulus is significantly reduced, and the extensibility greatly increased.

The aim of the present research is the optimization of silicone networks loaded with fillers in different concentrations to finally achieve a soft network with low viscous dissipation and high electrical permittivity, suitable as materials for DEAPs.

\section{THEORY}

The mechanical properties of polymer networks may be tuned by changing the molecular weight of the polymer chains and by varying the stoichiometric imbalance given by the molar ratio between the reactive groups of the crosslinker and the vinyl groups of the $\mathrm{PDMS}^{8-13}$ :

$$
r=\frac{f[H M S]_{0}}{2[P D M S]_{0}}
$$

where $f$ is the functionality of the crosslinker and $[\ldots]_{0}$ is the initial concentration of the crosslinker (HMS) and polymer (PDMS), respectively. For a stoichiometric mixture $\mathrm{r}=1$ and all reactive groups are involved in forming a so-called (ideal) model network. To prepare a soft network with excess of polymer, the stoichiometric imbalance needs to exceed the critical composition (the so-called gel point $r_{c}$ ) which defines the change from liquid to solid:

$$
r_{c}=\frac{1}{f-1}
$$

The polydimethylsiloxane (PDMS) network can be regarded as model network and is prepared via a well-defined crosslinking reaction ${ }^{14,15}$. Most model networks are prepared by a reaction between a multi-functional crosslinker and a linear polymer with reactive end-groups. At the end of reaction, as a result of either stoichiometrically imbalanced networks or due to incompleteness of reaction, there are different structures contributing to the elastic and viscous behaviors of the network: the elastically active chains, the dangling chains and substructures, the soluble chains and soluble substructures. Great effort was made to elucidate the influence of each type of polymer chains over the final properties of the system ${ }^{7,11}$.

The elastic properties of a polymer network are described in terms of the static shear modulus. Assuming incompressibility of the bulk phase of the network, which is a very reasonable assumption for silicone networks as the Poission's ratio is usually of the order of 0.49 , the relation between the Young's modulus and the static shear modulus is: 
Return to your MySPIE To Do List at http://myspie.org and approve or disapprove this submission. Your manuscript will not be published without this approval. Please contact author_help@spie.org with any questions or concerns.

$$
Y=3 G
$$

The static shear modulus of a polymer network can be written as a weighted function of the phantom and the affine models:

$$
G_{c}=\left(1-h \frac{2}{f}\right) v_{c} R T
$$

where $\mathrm{h}$ is a empirical parameter that can vary between 0 (affine model) and 1 (phantom model), $\mathrm{R}$ is the gas constant, $\mathrm{T}$ is the absolute temperature and $v_{\mathrm{c}}$ is the molar concentration of the crosslinks, which for the ideal network consisting of long elastically active chains only is given by:

$$
v_{c}=\frac{\rho}{M_{P D M S}}
$$

where $\rho$ is the density of the polymer ${ }^{16}$. For stoichiometrically imbalanced networks the concentration of elastically active chains has to be calculated from probability theories. Langley and Graessley proposed the addition of the entrapped entanglements to the equilibrium modulus ${ }^{17}$, leading to:

$$
G=G_{c}+G_{E}=\left(1-h \frac{2}{f}\right) v_{c} R T+T_{E} G_{0}
$$

where $T_{E}$ is the trapping factor (calculated from statistics) and $G_{0}$ is the entanglement modulus of long well-entangled chains with the same backbone structure as the elastic network chains ${ }^{18,19}$.

Mechanical reinforcement of networks is traditionally achieved by introducing fillers (micro- and nano-particles) in the elastomer base. Fillers in the network increase the contribution from trapped entanglement as the dynamics of the network becomes more restricted and a simple expression can be written as:

$$
G=G_{c}+G_{E}=\left(1-h \frac{2}{f}\right) v_{c} R T+G_{0, \text { trapped }}
$$

where $\mathrm{G}_{0 \text {,trapped }}$ is the modulus arising from polymer chains being entrapped by filler particles. No precise expression for this modulus exists because the effect is very dependent on combination of fillers and network.

\section{EXPERIMENTAL}

Materials

Silicone networks were prepared using $\alpha, \omega$-vinyl-poly(dimethyl siloxane) (V35, $\left.\mathrm{M}_{\mathrm{n}}=49500 \mathrm{~g} / \mathrm{mol}\right)$ as the polymer and tetrakis(dimethyl siloxy)-silane with $\mathrm{M}_{\mathrm{w}}=328 \mathrm{~g} / \mathrm{mol}$ as crosslinker (4- functional). All the polymers were purchased from Gelest Inc. and the given molecular weights were supplied by the company. The catalyst (platinum cyclovinylmethyl siloxane complex (511)) was provided by Hanse Chemie.

To reinforce the mechanical properties and increase the dielectric permittivity of the silicone networks simultaneously, different fillers were used: micro and nano-particles and nanoclays. The fillers were acquired from Sigma-Aldrich unless otherwise specified. Three types of silica particles were tested: amorphous hexamethyldisilazan treated silica particles (1-5 $\mu \mathrm{m}$ diameter) (denoted $\mathrm{T}-\mathrm{SiO}_{2}$ in the following), untreated silica particles $(1-5 \mu \mathrm{m})\left(\mathrm{U}_{-} \mathrm{SiO} \mathrm{S}_{2}\right)$ and fumed silica particles $(14 \mathrm{~nm}$ diameter $)\left(\mathrm{F}-\mathrm{SiO}_{2}\right)$. Additionally, barium titanate particles $\left(\mathrm{BaTiO}_{3}\right)(100 \mathrm{~nm})$ and pristine nanoclay 
Return to your MySPIE To Do List at http://myspie.org and approve or disapprove this submission. Your manuscript will not be published without this approval. Please contact author_help@spie.org with any questions or concerns.

(NC) montmorillonite were applied after freeze-drying from an aqueous dispersion and were used without further modification as fillers.

A commercial elastomer was purchased from Wacker Chemie (ElastosilRT 625) for comparison. Premixes A and B are mixed in the recommended mass ratio of a 9:1. Fillers are already included in both premixes.

Poly(tetrafluroethylene-co-hexafluorethylene) (FEP) foil with $100 \mu \mathrm{m}$ thickness is purchased from DuPont and is used as release liner for the networks.

Methods

Preparation of different silicone networks

ElastosilRT 625 samples were prepared from mixing of the A and B premixes at room temperature. The mixture was poured onto FEP foil and left to cure in a steel mould (Figure 1). The curing time at room temperature was determined to 10 hours.

Using the classical hydrosilylation reaction at room temperature $\left(23^{\circ} \mathrm{C}\right)$ between the linear polymer with vinyl functional end groups (V35) and a 4-functional crosslinker, so-called unimodal networks were synthesized. Unimodal refers to the polymer used in the preparation, which has a unimodal molecular weight distribution ensuring homogeneous distribution of the crosslinks. Details of the unimodal networks synthesis procedure have been explained in details elsewhere ${ }^{20,21}$.

The PDMS networks loaded with fillers were prepared at room temperature using 3 premixes denoted A, B and C, respectively. A schematic conceptualization of the synthesis procedure of the silicone networks with fillers is presented in Figure 2. Premix A contained PDMS and crosslinker, premix B contained PDMS and catalyst, and premix C contained PDMS and fillers. The purpose of the premix preparation was to ensure long time storage of the premixes and sufficient mixing of crosslinker and polymer, catalyst and polymer, and a good dispersion of the fillers in the polymer before the crosslinking reaction took place. The fillers in premix $\mathrm{C}$ were dispersed beforehand in heptane by thorough mechanical mixing and ultrasonication (30 minutes). The solvent was removed in vacuo, resulting in a premix with dispersed filler. Dispersion of fillers in solvent and further in the final mix is an important step for the homogeneity of the sample. The fillers in premix $\mathrm{C}$ were added in high concentration. Approximately $30 \mathrm{wt} \%$ of particles or $5 \mathrm{wt} \%$ of nanoclays allowed for mixing in the highly viscous polymer. When added to the final mix $(\mathrm{A}+\mathrm{B}+\mathrm{C})$ the quantity of premix $\mathrm{C}$ was calculated to obtain the desired final concentration of filler particles.

The 3 premixes were mixed in different ratios according to the final desired stoichiometric imbalance of the networks ( $\mathrm{r}$ $=1$ or 1.2$)$ and the appropriate concentration of the fillers $(1-5 \mathrm{wt} \% \text { or } 10-12 \mathrm{wt} \%)^{22,23}$. The mixture was poured onto the release liner in the steel mould to prepare samples comparable to the Elastosil reference samples above.

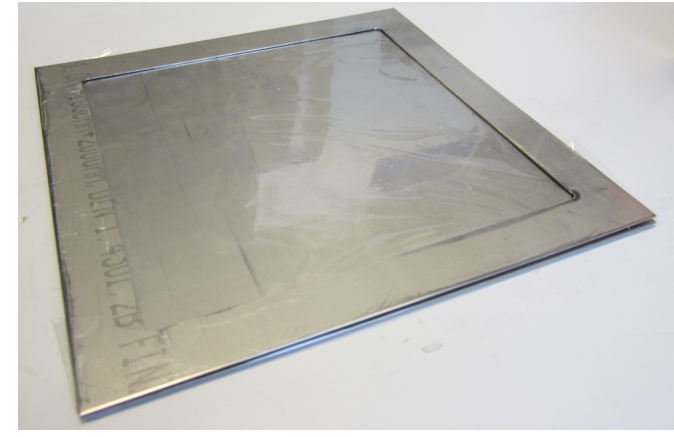

Figure 1. Picture of the steel squared mould and the FEP foil, used to form the networks with $25 \mathrm{~cm}$ length and $1 \mathrm{~mm}$ thickness.

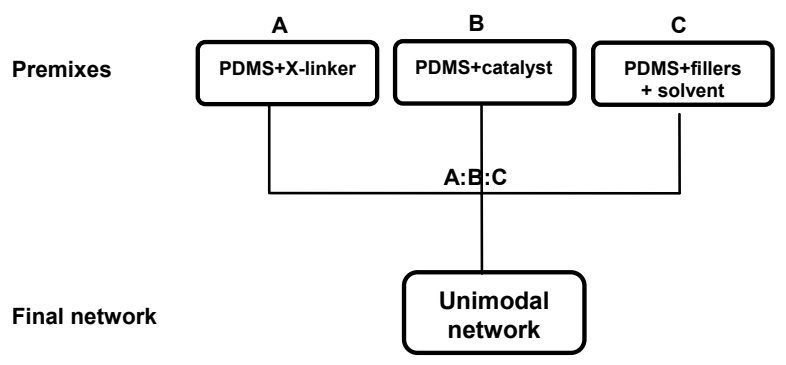

Figure 2. Conceptualization of the synthesis procedure of the silicone networks with fillers. The main principle is to keep the premixes inreactive by separating catalyst and crosslinker such that the 3 mixes can be mixed for long time to ensure dispersion and sufficient time for mixing. 
Return to your MySPIE To Do List at http://myspie.org and approve or disapprove this submission. Your manuscript will not be published without this approval. Please contact author_help@spie.org with any questions or concerns.

\section{Rheological characterization}

The rheological characterization was performed by a controlled stress rheometer (AR2000) from TA Instruments set to a controlled strain mode with $2 \%$ strain, which was ensured to be within the linear regime of the material based on an initial strain sweep. The applied geometry was parallel plates $(25 \mathrm{~mm})$ and the experiments were performed at $25^{\circ} \mathrm{C}$. The LVE diagrams were obtained from frequency sweeps from $100 \mathrm{~Hz}$ to $0.001 \mathrm{~Hz}$.

Dielectric characterization

Dielectric Relaxation Spectroscopy (DRS) was performed on a Novocontrol Alpha-A high performance frequency analyzer.

\section{Optical characterization}

Optical characterization was performed using an optical microscope (Leica DMLB) connected to a Highlight 2000 from Olympus.

\section{RESULTS AND DISCUSSION}

Networks without fillers and with different types of fillers and in different concentrations have been prepared in this study. Microparticles, nanoparticles and nanoclays are used to increase the dielectrical permittivity of the networks. Similar investigations have been performed by others ${ }^{24-26}$, however here we have put the emphasis on the combination of the filler to increase the dielectric strength and on maintaining a hight flexible network. The presence of fillers causes modifications to both dielectric and mechanical properties of the elastomers.

\section{Rheological characterization}

The influence of the fillers on the linear viscoelastic properties of the silicone networks can be investigated in a linear viscoelastic diagram (LVE diagram). The elastic modulus is determined from $\mathrm{G}^{\prime} \mathrm{G}^{\prime}(\omega \rightarrow 0)$. The dynamic behavior in the frequency regime $0.01-100 \mathrm{~Hz}$ was investigated.

In Figure 3 the viscoelastic behaviour as function of the applied frequency (LVE diagram) is shown for the commercial sample (ElastosilRT 625) and the experimental sample (V35-4f, $\mathrm{r}=1$ ) loaded with $3 \mathrm{wt} \% \mathrm{U}_{-} \mathrm{SiO}_{2}$ and without fillers, respectively. A decrease of $G$ ' with decreasing frequencies indicates viscous dissipation. No viscous dissipation can be observed for the commercial sample in the studied range of frequencies $(0.001$ and $100 \mathrm{~Hz})$ and the elastic modulus of ElastosilRT 625 is a factor of approximately 10 higher than the V35-4f $(\mathrm{r}=1)$ network without fillers. The low elastic modulus of the unfilled V35-4f network is due to the high molecular weight of the PDMS as well as the low functionality of the crosslinker. Furthermore the very small 4 -functional crosslinker is believed to cause steric hindrance such that $\mathrm{r}=1$ is not the ideal stoichiometry. This can also be seen by the fact that the $\mathrm{r}=1.2$ network has a significantly higher elastic modulus than the network with $\mathrm{r}=1.0$. Addition of a relatively small amount $(3 \mathrm{wt} \%)$ of $\mathrm{U}-\mathrm{SiO}_{2}$ particles causes an increase of the elastic modulus with a factor of 4 compared to the unfilled network, as the particles are acting as physical crosslinkers, which to a great deal stabilizes the material and makes it less prone to viscous dissipation.

In figure 4 a LVE diagram for the V35-4f $(r=1.2)$ network can be seen. Here the presence of different fillers in various concentrations in the nonstoichiometric networks also determines an increase in G', but the increase seems to be rather insignificant independently of the type or the concentration of the filler. The difference in the small-concentration limit investigated within this work is due to the higher degree of crosslinking within this material such that the elasticity effect caused by the fillers is small relative to the effect from the chemical crosslinks (i.e. $G_{0 \text {, trapped }} \ll G_{c}$ ).

The values of $\mathrm{G}$ for the investigated systems at $0.001 \mathrm{~Hz}$ and at $100 \mathrm{~Hz}$ are summarized in Table 1 . 
Return to your MySPIE To Do List at http://myspie.org and approve or disapprove this submission. Your manuscript will not be published without this approval. Please contact author_help@spie.org with any questions or concerns.

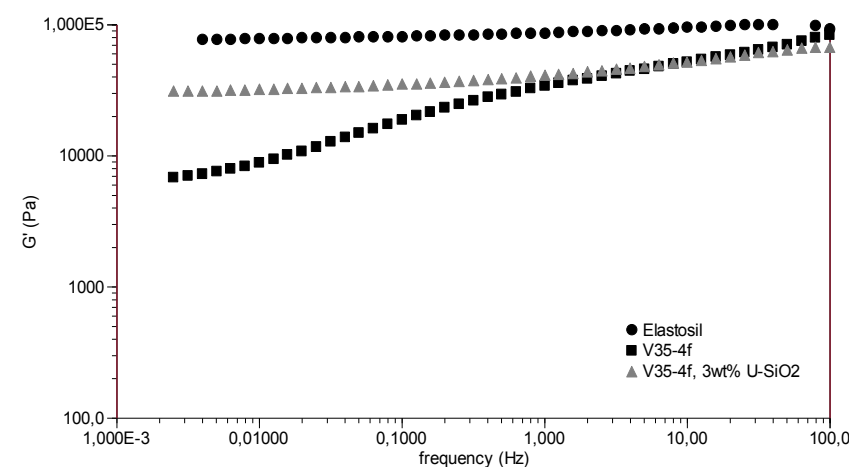

Figure 3. The influence of the fillers presence on the viscoelastic behavior of silicone networks with $\mathrm{r}=1$

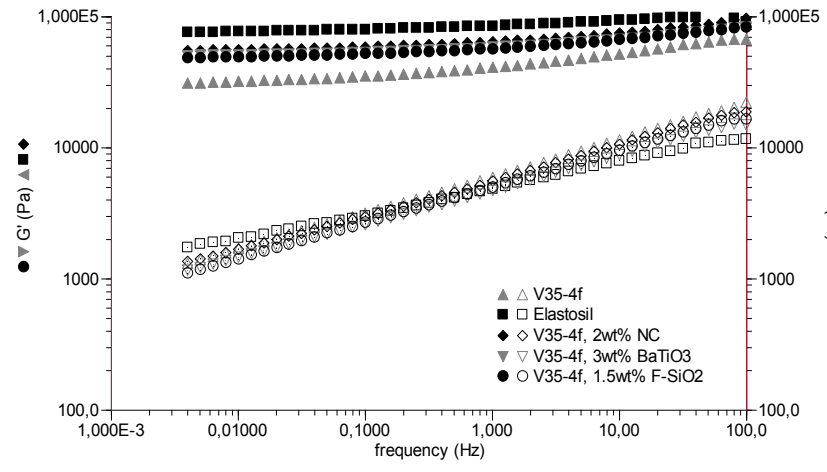

Figure 4. The viscoelastic behavior of silicone networks $(r=1.2)$ with different fillers in different concentrations

Different viscoelastic behaviour is observed for V35-4f networks when loaded with different concentrations of fumed silica particles $\left(0.5-3 \mathrm{wt} \% \mathrm{~F}-\mathrm{SiO}_{2}\right)$. The influence of $\mathrm{F}-\mathrm{SiO}_{2}$ concentrations on $\mathrm{G}$ ' for the $\mathrm{r}=1.2$ network is shown in Figure 5. An increase as expected of the elastic modulus with the percentage of the particles is measured but the effect is much smaller than for $\mathrm{r}=1$ network.

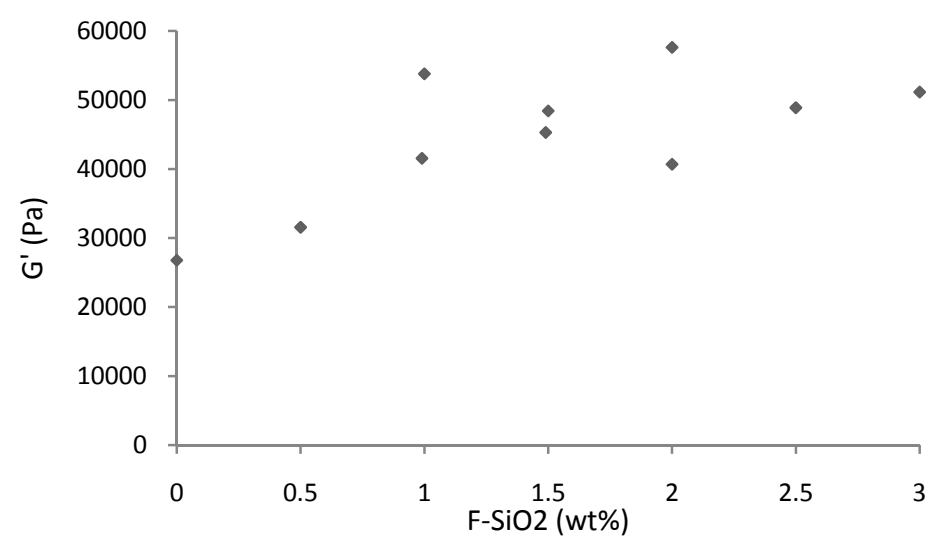

Figure 5. The influence of $\mathrm{F}-\mathrm{SiO}_{2}$ concentration (wt\%) on $\mathrm{G}^{\prime}$ for PDMS-V35 networks $(\mathrm{r}=1.2)$

From the results it is obvious that just an addition of a small amount of fumed silica particles has a tremendous effect on the elastic modulus of the very soft network $(\mathrm{G}=7 \mathrm{kPa})$. The addition of $1 \mathrm{wt} \% \mathrm{~F}_{-} \mathrm{SiO}_{2}$ leads to an increase of a factor of approximately 5. For larger amounts of $\mathrm{F}_{-} \mathrm{SiO}_{2}$ it seems that there are no big changes to the elastic modulus, and it becomes problematic to obtain a well-dispersed sample. It is, however, also found that even $3 \mathrm{wt} \%$ of $\mathrm{F}-\mathrm{SiO}_{2}$-despite the strong mechanical reinforcement - does not give the desired tear strength for processing of thin films.

\section{Dielectric characterization}

The dielectric properties of networks with different types and amounts of fillers are investigated at room temperature as a function of frequency $\left(0.1-10^{5} \mathrm{~Hz}\right)$ (Figure 6). 
Return to your MySPIE To Do List at http://myspie.org and approve or disapprove this submission. Your manuscript will not be published without this approval. Please contact author_help@spie.org with any questions or concerns.

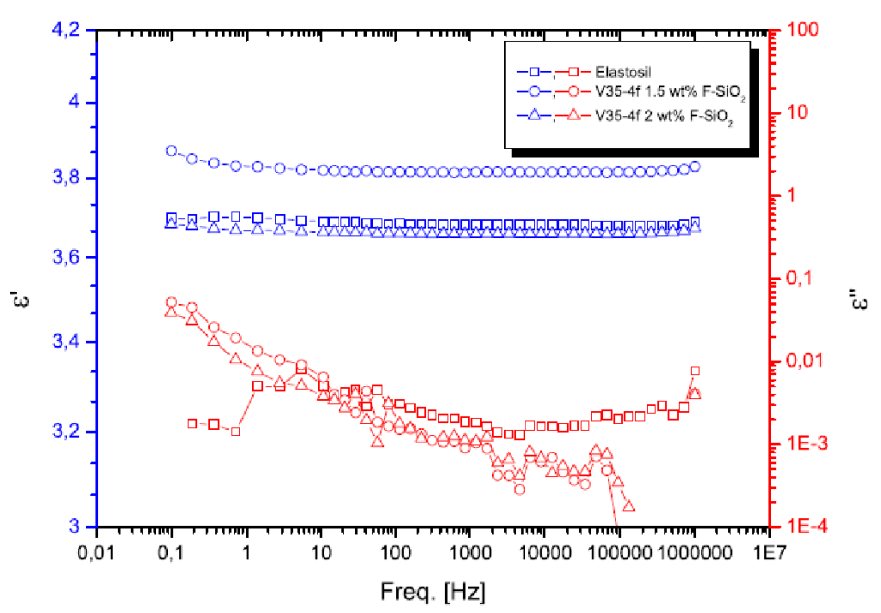

Figure 6. Real ( $\left.\varepsilon^{\prime}\right)$ and imaginary ( $\left.\varepsilon^{\prime \prime}\right)$ part of the complex permittivity for the elastocil reference sample and for the PDMS networks containing a variable amount of silica particles.

As can be seen in Figure 6, there are only minor differences in the real part of the permittivity of the different networks containing silica particles. The reference sample shows a permittivity that approximately equals that of the networks filled with fumed silica. This shows that even though the silica particles generally have a beneficial effect on tear strength of the network it is still necessary to increase the permittivity of the network in order to improve the performance of the elastomers as DEAP. In Figure 7 results from the investigation of networks containing either barium titanate or nanoclay is shown.

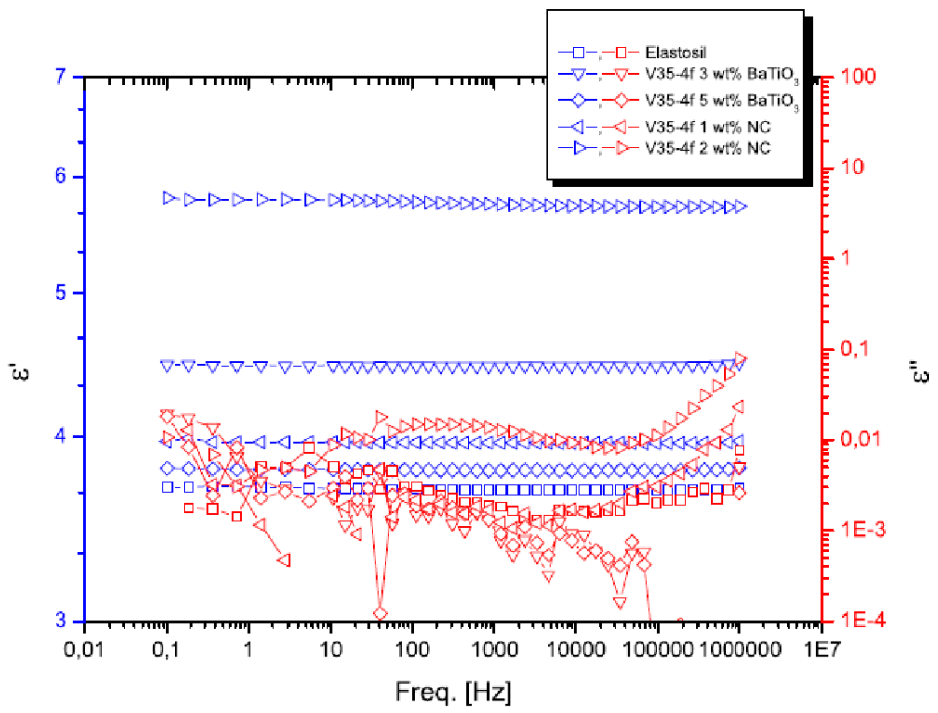

Figure 7. Real $\left(\varepsilon^{\prime}\right)$ and imaginary ( $\left.\varepsilon^{\prime \prime}\right)$ part of the complex permittivity for the elastocil reference sample and for the PDMS networks containing a variable amount of barium titanate or nanoclay.

It is clear from the trends in Figure 7 that the real part of the permittivity can be improved substantially with the right choice of filler. For the samples containing barium titanate there is an increase of about $33 \%$ at only a $3 \mathrm{wt} \%$ content of filler $\left(\varepsilon^{\prime}=4.5\right)$. An interesting detail here is that by a further increase of filler content to $5 \mathrm{wt} \%$ a decrease in permittivity is observed $\left(\varepsilon^{\prime}=3.8\right)$. This clearly shows the importance of proper dispersion of the filler. At the higher loading of filler it became substantially more difficult to disperse the particles properly, which resulted in agglomerated particles in the network and a decrease in permittivity. For the networks containing freezedried nanoclay also a substantial increase in permittivity is observed, where a permittivity of $\varepsilon_{\mathrm{r}} \sim 6(80 \%)$ can be seen for the sample with $2 \mathrm{wt} \%$ nanoclay. This is 
Return to your MySPIE To Do List at http://myspie.org and approve or disapprove this submission. Your manuscript will not be published without this approval. Please contact author_help@spie.org with any questions or concerns.

believed to be due to the high surface area of the nanoclay, that supports a charge stabilization in the polymer network. The effect is increased with higher loading of nanoclay, though also here a substantial agglomeration is observed.

Table1. Summary of samples characterized in this study (V35-4f) in absence or presence of fillers in different concentrations and their elastic modulus (at 0.001 and $100 \mathrm{~Hz}$ ) and dielectrical permittivity at $1 \mathrm{~Hz}$

\begin{tabular}{|c|c|c|c|c|c|c|}
\hline $\begin{array}{l}\text { Samples and } \\
\text { type of particle }\end{array}$ & $\begin{array}{c}\mathrm{wt} \% \\
\text { particle }\end{array}$ & $\mathrm{r}$ & $\begin{array}{c}\mathrm{G}^{\prime} \text { at } 0.001 \mathrm{~Hz} \\
(\mathrm{kPa})\end{array}$ & $\begin{array}{c}\mathrm{G}^{\prime} \text { at } 100 \mathrm{~Hz} \\
(\mathrm{kPa})\end{array}$ & $\frac{\mathbf{G}^{\prime}(100 \mathrm{~Hz})-\mathbf{G}^{\prime}(0.01 \mathrm{~Hz})}{\mathbf{G}^{\prime}(100 \mathrm{~Hz})}$ & $\varepsilon_{\mathrm{r}}$ at $1 \mathrm{~Hz}$ \\
\hline ElastosilRT 625 & - & - & 76.6 & 99.3 & 0.228 & 3.2 \\
\hline \multirow[t]{2}{*}{ V35-4f } & - & 1 & 6.74 & 84.2 & 0.919 & \\
\hline & & 1.2 & 26.7 & 63.6 & 0.579 & \\
\hline \multirow[t]{2}{*}{$\mathrm{U}-\mathrm{SiO}_{2}$} & 3 & 1.2 & 68.4 & 93.5 & 0.268 & 2.3 \\
\hline & 5 & 1.2 & 66.5 & 97.1 & 0.315 & 2.6 \\
\hline \multirow[t]{2}{*}{$\mathrm{T}-\mathrm{SiO}_{2}$} & 11 & 1 & 25.3 & 71 & 0.643 & \\
\hline & 12 & 1 & 27 & 70.8 & 0.618 & 2.3 \\
\hline \multirow{3}{*}{$\mathrm{F}-\mathrm{SiO}$} & 1 & 1.2 & 41.5 & 70.3 & 0.409 & 2.2 \\
\hline & 1.5 & 1.2 & 48.4 & 81 & 0.402 & 1.9 \\
\hline & 2 & 1.2 & 57.6 & 88.2 & 0.346 & 3.6 \\
\hline \multirow[t]{2}{*}{$\mathrm{BaTiO}_{3}$} & 3 & 1.2 & 50.8 & 84 & 0.395 & 4.5 \\
\hline & 5 & 1.2 & 24.2 & 49.4 & 0.510 & 3.8 \\
\hline \multirow[t]{2}{*}{ Nanoclays } & 1 & 1.2 & 44.1 & 77.3 & 0.429 & 3.9 \\
\hline & 2 & 1.2 & 55.6 & 97.7 & 0.430 & 5.8 \\
\hline
\end{tabular}

\section{Optical characterization}

All the samples were investigated by optical microscopy in order to evaluate the dispersion of the particles as shown with two examples in Figure 8a and b for the reference sample and a sample containing nanoclay.
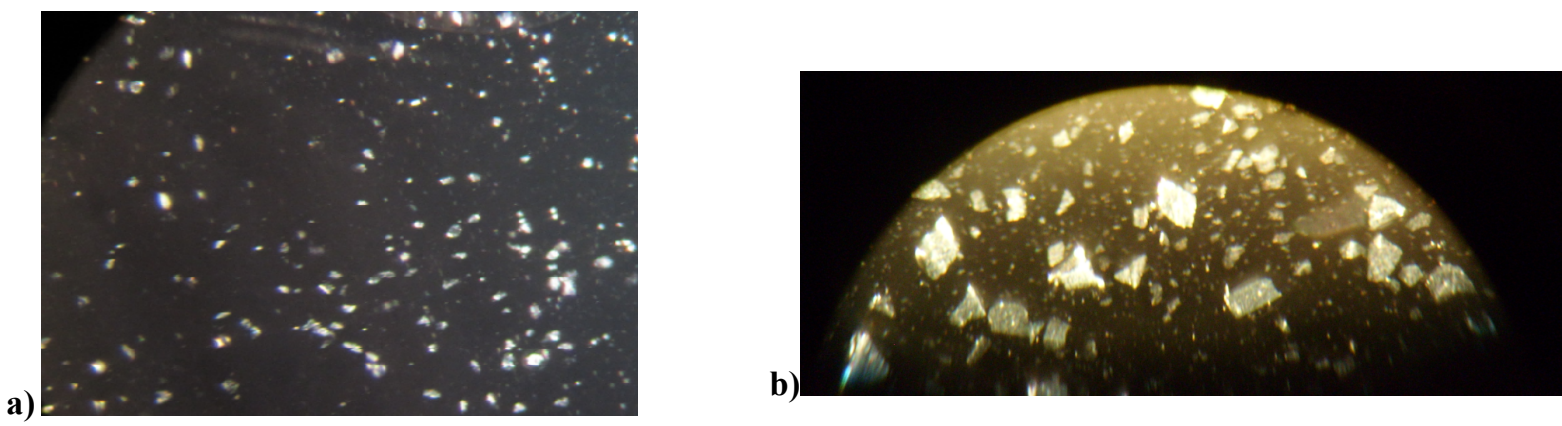

Figure 8. Optical microscopy pictures with a magnification of 400 are taken for a) ElastosilRT 625 networks loaded with microparticles of $6 \mu \mathrm{m}$ and b) PDMS-V35 networks loaded with $\mathrm{NC}$ - pellets with 300x300x1 nm.

As can clearly be seen from the Figure 8a the reference sample contains some large particles. This is expected as a size distribution investigation of the sample showed the presence of agglomerates in the premix. Similarly, relatively poor dispersion was observed for the nanoclay filled network in Figure 8b. Even though the sample shows the presence of some large agglomerates a substantially increased permittivity was observed for the sample as shown above.

\section{CONCLUSIONS}

The effects of different micro- and nanofillers on the electro-mechanical behavior of silicone based dielectric elastomer are studied in this work. Several types of fillers and varied loadings are used to increase the overall permittivity of the 
Return to your MySPIE To Do List at http://myspie.org and approve or disapprove this submission. Your manuscript will not be published without this approval. Please contact author_help@spie.org with any questions or concerns.

silicone networks. Nanoclays and barium titanate seem to be good candidates for enhancement of the dielectric permittivity of the silicone networks, but they need to be combined with either other particles that enhance the tear strength of the material or bimodal networks.

\section{AKNOWLEDGEMENTS}

The authors would like to acknowledge the financial support from Danish Agency for Science, Technology and Innovation, and the Danish National Advanced Technology Foundation.

\section{REFERENCES}

[1] Basuli, U., Chaki, T. K. and Naskar, K., "Mechanical properties of thermoplastic elastomers based on silicone rubber and an ethylene-octene copolymer by dynamic vulcanization," Journal of Applied Polymer Science (108), 1079-85 (2008).

[2] Zhang, Z., Liu, Y. and Leng, J., "Effects of conductive particles on the actuating behavior of dielectric elastomer actuator," Conference on Electroactive Polymer Actuators and Devices (EAPAD), San Diego, CA (2010).

[3] Risse, S., Kussmaul, B., Krueger, H., Wache, R. and Kofod, G., "DEA material enhancement with dipole grafted PDMS networks," Conference on Electroactive Polymer Actuators and Devices (EAPAD), San Diego, CA (2011).

[4] Kussmaul, B., Risse, S., Kofod, G., Wache, R., Wegener, M., McCarthy, DN., "Enhancement Of Dielectric Permittivity And Electromechanical Response In Silicone Elastomers: Molecular Grafting Of Organic Dipoles To The Macromolecular Network", Advanced Functional Materials (21) 4589-94 (2011).

[5] Opris, D.M., Molberg, M., Walder, C., Ko, Y.S., Fischer, B. and Nueesch F.A., "New Silicone Composites for Dielectric Elastomer Actuator Applications In Competition with Acrylic Foil" (21). Advanced Functional Material (21) 3531-9 (2011).

[6] Brochu, P. and Pei, Q., "Advances in Dielectric Elastomers for Actuators and Artificial Muscles," Macromolecular Rapid Communications, (31) 10-36 (2010).

[7] Mark, J.E., "Bimodal networks and networks reinforced by the insitu precipitation of silica," British Polymer Journal (17), 144-8 (1985).

[8] Patel, S.K. and Cohen, C.," Dynamic light-scattering from swollen poly(dimethylsiloxane) networks," Macromolecules (25), 5252-8 (1992).

[9] Gent, A.N. and Tobias, R.H., "Diffusion and equilibrium swelling of macromolecular networks by their linear homologs," J. of Polym. Sci. Part B-Polymer Physics (20), 2317-27 (1982).

[10] Sharaf, M.A., Mark, J.E. and Ahmed, E., "Elastomeric properties of end-linked networks of high cross-link functionality with extent of reaction and chain-length distribution," Colloid and Polymer Science (272), 504-15 (1994).

[11] Gottlieb, M., Macosko, C.W., Benjamin, G.S., Meyers, K.O. and Merrill E.W., " Equilibrium modulus of model poly(dimethylsiloxane) networks", Macromolecules (14), 1039-46 (1981).

[12] Macosko, C.W. and Benjamin, G.S., "Modulus of 3-functional and 4-functional poly(dimethylsiloxane) network," Pure and Applied Chemistry (53), 1505-18 (1981). 
Return to your MySPIE To Do List at http://myspie.org and approve or disapprove this submission. Your manuscript will not be published without this approval. Please contact author_help@spie.org with any questions or concerns.

[13] Larsen, A.L., Hansen, K., Sommer-Larsen, P., Hassager, O., Bach, A., Ndoni S, et al., "Elastic properties of nonstoichiometric reacted PDMS networks," Macromolecules (36), 10063-70 (2003).

[14] Pelrine, R., Kornbluh, R., Joseph, J., Heydt, R., Pei, Q.B. and Chiba S., "High-field deformation of elastomeric dielectrics for actuators," Materials Science \& Engineering C-Biomimetic and Supramolecular Systems (11), 89-100 (2000).

[15] Chambon, F. and Winter, H.H., "Linear viscoelasticity of the gel point of a cross-linking PDMS with imbalanced stoichiometry, Journal of Rheology (31), 683-97 (1987).

[16] Dossin, L.M. and Graessley, W.W., "Rubber elasticity of well-charactertized polybutadiene networks," Macromolecules (12), 123-30 (1979).

[17] Langley, N.R. and Polmante,Ke., "Role of chain entanglements in rubber elasticity," Abstracts of Papers of the American Chemical Society (42) (1972).

[18] Villar, M.A., Bibbo, M.A. and Valles, E.M., "Influence of pendant chains on mechanical properties of model poly(dimethylsiloxane) networks .1. Analysis of the molecular structure of the network," Macromolecules (29), 4072-80 (1996).

[19] Villar, M.A. and Valles, E.M., "Influence of pendant chains on mechanical properties of model poly(dimethylsiloxane) networks .2. Viscoelastic properties," Macromolecules (29) 4081-9 (1996).

[20] Rasmussen, H.K., Bejenariu, A.G., Hassager, O. and Auhl, D., "Experimental evaluation of the pure configurational stress assumption in the flow dynamics of entangled polymer melts," Journal of Rheology (54). 1325-36 (2010).

[21] Bejenariu, A.G., Yu, L., Skov, A.L., "Low moduli elastomers with low viscous dissipation," Soft Matter, DOI $=10.1039 / \mathrm{b} 803770 \mathrm{c}(2012)$

[22] Bejenariu, A.G., Boll, M., Lotz, M.R., Vraa, C., Skov, A.L., "New elastomeric silicone based networks applicable as electroactive systems," Conference on Electroactive Polymer Actuators and Devices (EAPAD), San Diego, CA (2011).

[23] Bejenariu, A.G., Rasmussen, H.K., Skov, A.L., Hassager, O. and Frankaer, S.M., "Large amplitude oscillatory extension of soft polymeric networks," Rheologica Acta (49) 807-14 (2010).

[24] Huang, C., Zhang, Q.M., deBotton, G. and Bhattacharya, K., "All-organic dielectric-percolative three-component composite materials with high electromechanical response," Applied Physics Letters (84), 4391-3 (2004).

[25] Gallone, G., Carpi, F., De Rossi, D., Levita, G. and Marchetti A., "Dielectric constant enhancement in a silicone elastomer filled with lead magnesium niobate-lead titanate," Materials Science \& Engineering C-Biomimetic and Supramolecular Systems (27), 110-6 (2007).

[26] Lotz, P., Matysek, M., Flittner, K. and Schlaak, H.F., "Reduction of the Driving Voltage in Dielectric Elastomer Actuators,"11th International Conference on New Actuators/5th International Exhibition on Smart Actuators and Drive Systems. Bremen, 868-71 (2008).

8340 - 20 V. 1 (p.10 of 10) / Color: No / Format: A4 / Date: 2012-02-13 11:28:36 AM 